\title{
Organic Farming Impact on Sustainable Livelihoods of Marginal Farmers in Shimoga District of Karnataka
}

\author{
Nazeer Udin* \\ Centre for Rural Development Studies, Bangalore University Bangalore, Karnataka, India \\ *Corresponding author: rdnazeer@gmail.com
}

Received August 07, 2014; Revised November 22, 2014; Accepted December 24, 2014

\begin{abstract}
In developing countries, where three out of four poor people live in rural areas and where more than $80 \%$ of rural people live in households that are involved in agriculture, improving poor farmers' livelihoods is central for addressing rural development. In recent times, organic farming has increasingly gained attention as a way to manage natural resources in a more sustainable way and to raise incomes especially of smallholder farms. To analyze the impact and the adoption of organic farming from a livelihood perspective hence requires not only considering measurable factors, but also investigate the perceptions and the rationale of the people involved. In this back drop, this study deals with impact of organic farming on sustainable livelihoods marginal organic farmers in Shimoga, Karnataka state India. It makes an attempt to assess organic farming impact on farmer's income, prices and family needs of their food consumption. it also compares the organic farming supported by Government as well as individuals efforts. Study is based on both primary and secondary data and selected individual case studies. The case study methods drawn from Rapid Rural Appraisal (RRA) while trying to embody the principles of Participatory Rural Appraisal (PRA) Methods. The study revealed that the organic farming not only fulfill the requirement family consumption but also give fair amount of income and reduce the cost of cultivation with a sustainability of agro eco system .further it concluded that Government support is only supplementary in nature and individual efforts have to come from a innovative perceptions of the farmers with a philosophical attitude towards integrated approach to farming system keep in view of ecological, economical and rural social setting for sustainability. The study indicates that there is a wide scope of diversification of farming practices such as Manure, water and Pest management and also generation of rural employment, provides food security at the house hold level where all these are possible actions with a maximum utilization of local natural capital inputs may offer the best prospects for poverty reduction and sustainable livelihood outcomes. However, the need of the hour is to promote organic farming by increasing capacity building of the farmers through interventions of expertise NGOS. and Government support. The study also found that there is a much scope to establish organic input preparation units in nearby villages and observed that the study area has favorable agro climatic conditions suitable for organic farming for marginal farmers are concerned.
\end{abstract}

Keywords: agriculture, organic farming, sustainable, livelihood, environment, marginal farmers

Cite This Article: Nazeer Udin, "Organic Farming Impact on Sustainable Livelihoods of Marginal Farmers in Shimoga District of Karnataka." American Journal of Rural Development, vol. 2, no. 4 (2014): 81-88. doi: 10.12691/ajrd-2-4-4.

\section{Introduction}

Agriculture has not only provided people with food, clothing and heating for several centuries, but it has also granted livelihoods to majority of the population around the world. Today, despite major innovations and new technologies, food production relies predominantly on the primary sector, which continues to be the backbone of India's economy.

An average Indian still spends almost half of his/her total expenditure on food, while roughly halfof India's work force is still engaged in agriculture for its livelihood. Being a source of livelihood and food security for a vast majority of low income, poor and vulnerable sections of society. India ranks134 in the Human Development Report. As per Planning Commission over the last decade, poverty has witnessed a consistent decline with the levels dropping from $37.2 \%$ in $2004-05$ to $29.8 \%$ in $2009-10$. Poverty in India declined to a record 22\% in 2011-12, With regard to being self-sufficient,

As per Central Statistical Organization, (CSO) the agriculture and allied sector had grown at $1.9 \%$ during 2012-13. As per estimates released by CSO on 29.11.2013. Increasing the production and productivity of Indian agriculture and ensuring food security are among the key priority areas of the government. To increase the production of agricultural crops and ensure food security for the growing population in the c(country). The agriculture sector witnessed steady decline in growth rate from 7.9 per cent in 2010-11 to 3.6 per cent in 2011-12 and further to 1.9 percent in 2012-13 [1] To meet the food demand is a great challenge under rapid environment degradation where the rural poor are heavily concentrated 
in areas of poor land quality (i.e. low potential agriculture, fragile ecology, weak. infrastructure, poor connectivity, and weakly functioning markets), yet the strong majority depend upon this land to support agricultural production to sustain their livelihoods and secure household food stocks. It is estimated that more than half of the world's population lives in marginal lands, a large proportion of which is prone to frequent shocks of droughts. Hence, about half of the two million people living in households from all socioeconomic classifications in the village, dry land regions are likely to be poor [2], Environmental degradation most severely affects the rural poor of the developing countries.

Environmental problems including soil erosion, floods, droughts, and pollution threatens the livelihoods of 2.6 billion people globally [3] yet, poverty itself intensifies the struggle for survival and leaves the poor with few options to maintain environmentally sustainable livelihoods.

Most of India's rural poor depend on rain-fed agriculture and fragile forests for their livelihoods. Agriculture is the largest economic sector in India, and it plays significant role in the growth and development of the national economy. Thus, the weakening of the agricultural sector over the last few decades is a major concern for the country in its ascent as an emerging market economy. According to the World Bank, the agrarian crisis in India is characterized by a slowdown in agricultural growth, low agricultural productivity, increasing natural resources degradation, and agricultural subsidies crowding out productivity enhancing investments [4]. The deterioration of agricultural performance is caused by a multitude of factors that go well beyond recent monsoon failures and include ecological, socio-political, and economic causes. Agricultural development, poverty reduction, and environmental protection have become closely interlinked, and an improved stewardship of natural resources will be critical for the future of agriculture.

\section{Section 1}

Organic agriculture is a nature-based farming system foregoing the use of chemical fertilizers, pesticides, livestock feed additives and growth regulators [5]. On a more general term, GEHLOT [6] describes organic farming as the 'process of producing food naturally' However, It is found that LAMPKIN [7] offers the most comprehensive definition. Apart from chemical-free input agriculture, he reflects the approaches and methods used in organic farming, pointing out the important role of recycling organic wastes to increase soil health and productivity and control insects, pests and weeds. In more technical terms, he explains the goal of organic agriculture as following

Although there are no universally accepted rules for organic farming, the review of literature denotes a concept of an environmental friendly way of agriculture. The farmers convert the soil from a non-living to a living organism applying techniques such as crop rotation and application of bio pesticides and bio fertilizers.

The principal concept is that organic farming is the farming based on natural principles which alone are sustainable." [8] In a nutshell, the most salient feature of organic farming is the absence of chemical inputs to increase productivity. The soil, and not the crops, is fed on a natural and integral basis. It is conspicuous that the definitions of authors vary from a technical to a more philosophical approach to an alternative form of agriculture. However, all sources do follow the maxim of environment protection and ecological sustainability.

\subsection{Organic Agriculture and the Environment}

Organic agriculture was developed as a farming system that is specifically aimed at producing food in a more environmentally friendly approach. On a productivity basis, organic agriculture has been shown to have several environmental benefits compared to conventional agriculture.

To, assess the potential contribution of organic agriculture to sustainable rural development, we need to understand (1) the environmental benefits and (2) the yield potential of organic agriculture, as well as (3) the impact of organic agriculture on farmer's livelihoods and (4) its accessibility to poor farmers. There is a need of the hour in changing paradigm of agriculture at global national and regional level which requires the scientific evidence on these four dimensions, identifying the problems and benefits of organic agriculture in developing country like India The large majority of studies on the environmental impact of organic agriculture have, however, been conducted in developed countries The environmental performance of organic agriculture in tropical systems and in developing countries thus remains to be examined thoroughly.

\subsection{Organic Agriculture and Farmer's Liveli Hood}

In developing countries, where three out of four poor people live in rural areas and where more than $80 \%$ of rural people live in households that are involved in agriculture, improving poor farmers' livelihoods is central for addressing rural development [9] Many studies have suggested that 'organic' agriculture could contribute substantially to farmers' food security and improve farmers' livelihoods [10,11,12,13,14].

Rural livelihoods are not limited just to income derived solely from farming but it is a holistic way of looking on their livelihood strategies. As far as strategies are concerned, Scoones and Ellis [15,16] considered agricultural intensification livelihood diversification and migration as the three core livelihood strategies.

\section{The way ahead}

Despite the shortcoming of current studies in providing solid proof, an increasing body of literature supports the claim of sustainable yield increases in low-input systems through agro ecological methods like agro forestry, integrated pest management, or the use of leguminous green manures $[17,18,19,20,21]$. To verify the claim that organic agriculture could lead to yield increases in smallholder agriculture, there is thus a strong need for similarly well-designed long-term studies that examine the yields of truly organic systems in smallholder agriculture

\subsection{Objectives and Scope of the Study}

The study is limited to marginal farmers (compare Figure 1) as they represent the majority and most vulnerable part of the rural population. The paper aims to 
contribute to the discussion of poverty alleviation and rural development by examining the concept of sustainable livelihoods and organic farming. It documents case studies of successful marginal organic farmers in Shimoga, assesses the impact of organic farming on farmers and their families, and whether or not it is contributory to a sustainable livelihood. Hence, the study intends to answer the research questions.

1. To specify the impact of organic farming on marginal farmers in terms of -Employment Reduced poverty and

\section{Farmers in Thirthahalli}

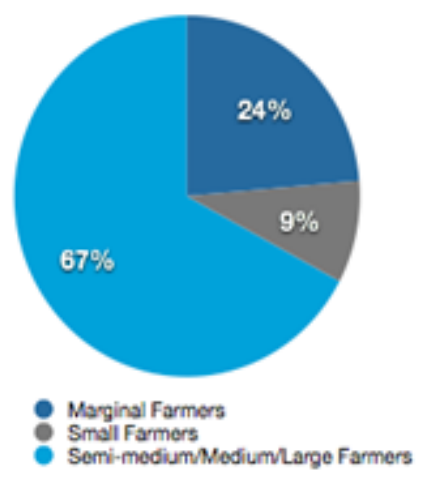

improve Well-being and capabilities resilience to shocks natural resource-based sustainability.

2. To draw a comparative analysis between marginal organic farmers and individual marginal organic farmers with irrigation facilities

3. To study the contribution of organic farming to sustainable livelihood development among marginal farmers in the respective situations, and illustrate the hindering and enabling factors.

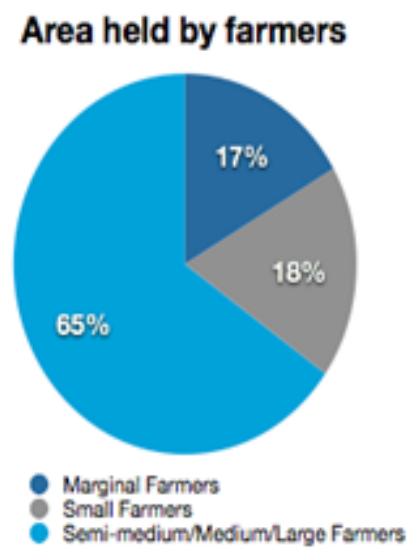

Figure 1. Landholding in Thirthahalli, Shimoga district (Source: AgriculturalCensus)

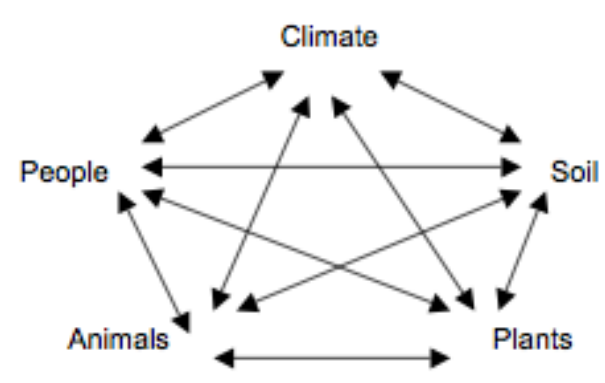

Figure 2. Organic agriculture as an integrative approach to farming (Source: Author)

\subsection{Methodology}

In order to answer the stated objectives a farmercentered research approach was chosen. The design of the study aims to capture the perceptions and realities of farmers practicing organic agriculture. Farmer families in Thirthahalli Taluk Shimoga district holding up to 1 acre of land were visited in the month of May 2012 and with the help of the case study methodology, living patterns, attitudes and farming practices were documented. More specifically, data was collected through semi-structured interviews, direct observation and talks with various stakeholders concerned with organic farming. the study is based on field observation which contributes to existing field of knowledge and intends to give an insight into the realities of farmers families. This consequently can assist other researchers and institutes to in generating hypothesis for further studies in the field of organic farming and sustainable livelihoods. The multiple case study approach is designed to depict individual cases of marginal organic farmers or phenomena a in a real-life context with the help of a variety of data collection.

\subsection{Background of the Study Area}

Thirthahalli is a urban body panchayat town and also taluk head quarters in the district of Shimoga which is situated in the Malnad region surrounded by the Western Ghats, the West of Karnataka. As per the Population Census India 2011, Shimoga counted a population of $1,755,512$ with a female-male ratio of 995 to 1000 lying well above the national average.

The district's most important sector is agriculture employing around 70 per cent of the population and contributing about 70 per cent to the overall district economy. Besides the areca nuts, the main cash crop, the region is also known as the rice bowl of Karnataka. (Gateway to Shimoga). Taluk constitutes nearly 67 percent of semi-medium / large farmers and remaining 24 and 9 percent are marginal small farmersrespectivelly.

The region is known for its progressive farmers and its role in organic farming in the state and the country. The organization namely KrishiPrayogaPariwara (KPP) and its founder, Mr.Purushothama Rao played a major role in promoting non-chemical agriculture in the district..The present director of the non-profit organization was also a key person during the field research.

\subsection{Impacts of Organic Production on Marginal Farmers}

The Impacts of a shift to organic production on the different types of production, on incomes and on the quality of the lives of marginal farmers. These issues have been analyzed through a set of case studies of marginal farmer groups that have been successful in adopting organic technologies and in marketing their organic products

The cases include the following: (a) Areca nut production (b) Paddy production; (c) the production of Spices (d) the production of fresh vegetables. The study has covered four marginal farmers with minimum 5 years experience in practice of organic farming.There are 
various motivational factors to adopt organic system. The followingmotivations were given:

- To improve the fertility of their soil;

- To reduce production costs (especially for fertilizers and pesticides);

- To reduce the risk of production (e.g. due to drought);

- To achieve a better price (premium);

- To be less dependent on loans.

\section{Case and Analysis}

\section{Section 2}

\subsection{CASE 1 - Manjuswamy Family}

Manjuswamy aged 49 with son and daughter living in one-acre farmland with their parents and grandparents. He got high school education. The family owns one acre of areca palms (Areca catechu), which provides the main income for their livelihoods. The areca nut or betel nut is a popular cash crop in the Malnad region of Thirthahalli. Its harvesting time is once a year around November to December, they managed with family labourbut during peak agricultural season hired labour utilized. If the prices in the market are stable, the family earns around one lakh Rupees for twelve quintals of areca nut, out of which they have to pay the wages for the laborers. Apart from the areca nut or adake, (local name ) his wife grows plenty of vegetables, fruits spicesbananas and jackfruit,etc. the women members cultivate pepper, coffee, cardamom, clove and chilies for their own consumption. There is monkey mence damaging crops but they belived that it is a symbolic of Hindu god- Anjaeya, Manjuswamy not getting any support from the government and they do not have irrigation facilities in their farm.

\subsection{Case 2 - Baswaraj Family}

Baswaraj is 28 years old and educated up to P. U. C Level lives with his mother in a big, newly renovated farmhouse in one-acre land. His father passed away a couple of years back and since then he is taking care of the the family property, the areca nuts have been cultivated solely with organic farming practices. His father's friends advised Baswaraj to use chemicals, but he refused.

During harvesting time, he asks his friends and neighbors for help and in return he would work on their farms when needed. He believes in doing hard work and barely requires paid labourers. He manages the farm work and mother take care of domestic work.

Earlier, Baswaraj used to harvest around two quintal of the areca nut, but ever since he invested in an irrigation system he is able to sell around twelve quintals in the market. Apart from that, he grows pepper and produces honey for own consumption. Next year, he is getting married and hopes thatthen his wife can also help in the farming activities.. He thinks even when they will have children the income from the farm itself will be sufficient. As a Brahmin family with around 400 areca palms, Basavaraj does not get any government support.

\subsection{Case 3 - Puttaiah Family}

Puttiah is a l paddy grower aged about 45 years and a literatePuttiah's father passed away and left 2 acres and 12 guntas to his four sons. According to local tradition, every son gets an equal Share of the family property. Today, Puttiah lives together with his wife and his two children

$\mathrm{He}$ adopted organic farming practices when KrishiPrayogaPariwara came to his village to promote sustainable agriculture. He used to apply a very minimum quantity of chemical fertilizers, but since the implementation of the project he calls himself a 100 per cent organic farmer. Now he applies around 100 baskets of farmyard manure, produced by his own cattle's. His wife Nagi grows radish, ginger and other vegetables on parts of the land.

All together he manages to harvest 20 quintals of paddy for which he can fetch around 30 per cent more in the marketas compared to chemically purchased paddy. He sold around 10 quintles for which he gets around 13,500 Rupees. Like other farmers, Puttiah also cultivates around 100 areca palms on encroached common land out of which he gets half a quintal. As an Schedule Caste, Puttiah, wife Nagi and their children got some benefits from the government through the help of KrishiPrayogaPariwara( NGO ). Among the benefits are free toilet and paddy storage facilities, cattle shed flooring and special containers to collect cow urine.

\subsection{Case 4 - Mahadeviah family}

Mahadeviah aged 49 years living with a two acresofland growing areca palms and half an acre of paddy. Now they are living in the small, but newly renovated house with $\mathrm{TV}$ and new furniture. Their daughter got married only last month and together with her husband she stays in the neighboring village. Her brother, Mahadeviah's son, works in Bangalore. He sends money on a regular basis so the family can cover the extra expenditures such as the wedding function and new purchases for the house. For food consumption the couple grows as much as possible on their own farm. Mahadeviah's pride is his cattles.He owns 12 cattle's in total, mainly Malnad local breed, but he has got buffaloes also. For half an acre of rice and a few areca nut plants he needs around 200 baskets of organic manure. The rest of the farmyard manure he can sell to other farmers. As a small paddy farmer he has got subsidies from the government for cow shed flooring, paddy storage and cow urine collection facilities.

\section{Results and Discussions}

\section{Impact on Liveli hoods \\ Employment Generation}

It is found that the farmers experienced a very labor intensive period during harvesting time after the monsoons in November and December. While the first and second cases claim to hired laborers for ploughing and harvesting the areca nut, the paddy cultivators rely more on help from neighbors' and friends. However, in all the studied cases the family is the primary source of labour except the first case

The informant from KrishiPrayogaPariwara also confirmed the importance of exchange of labour among organic farmers in the form of non-monetary support. He also added that the advantage of small farmers with less than one acre of land do have the advantage of less labour 
requirement, which can be covered by the family members internally.

one areca nut farmer and one paddy farmer are involved in only farm works for around three month in a year. Another paddy cultivator is occupied for around eight months in a year in farm work only and the other respondent, a young bachelor pursues farming as a fulltime activity. None of the four farmers feel extra burden of organic farming as compared to non-organic agriculture. While the first two interviewees had never applied chemicals before, the paddy farmers used toapply anddo not feel a difference.

\section{Food for family consumption}

It was found that afew of the families are self-sufficient in their food consumption. While the families with more members in the household are growing more vegetables, fruits and spices for their consumption at home, the others stated that they purchased s from outside. However, three respondents wish to grow more on their own farm. The farmers who grow paddy generally produce for their own requirements whereas the cash crop cultivators have to purchase the staple food items from the town city. The informants on the other hand expressed the importance of mixed cropping for marginal farmers

\section{Increase in income}

Out of the four interviewed farmer families, only one generates enough income exclusively from farm related activities. The head of the other families go for other jobs outside their farm varying from masonry to driving an auto rickshaw, mechanic work, agricultural labourer it is observed that, there is a need of extra income for education of children or religious ceremonies expenditure etc., In terms of premium prices, the farmers cultivating cash crops fetch premium prices.But varies due to market fluctuations. While the paddy farmers get around 35 per cent as a premium for organically grown rice.

The same incentive might work in the overall crop rotation in the farm. If farmers received a price premium also for the rotation crops, more diverse rotation patterns might be achieved Altogether the results support the hypothesis that cropping patterns in organic areca nut farms are more diverse than in conventional farms (earlier practiced)

All four respondents found that, the yieldlevel in organic farming is the less than the chemical agriculture. and also cost of cultivation isless keeping the sustainability of farming land in the long run.

\section{Adequate and healthy food products}

It is observed that, most of the respondent families growing vegetables and fruits rather than food crops. The first two respondents are cultivating cash crops and hence they have to buy staple food items such as rice, wheat from stores. Nonetheless, all of the interviewees said that they had sufficient income to cover the daily food expenses.As a food crop onefarmer stated however that, ever since he iscultivating rice for family consumption as a result, his health problems have come down drastically and he feels healthier dueto nutritivevalue of food is more when compare to chemically grown

\section{Resilience to climatic shocks}

It was found that although all families believed that, areca nut trees are pest resistant and also got high resilience to heavy rains and drought.Organically grown crops with local varieties are strongagainst weather shocks in a long-term basis. Further it is claimed that, due to erratic rains and fluctuating prices, revenues from areca nut production are insecure.

As organic farming involves less production cost and especially less input cost, the financial loss in case of crop failure or price depression is lower than in conventional farming. We found some indications that organic management can improve soil structure and therefore reduce the crop's susceptibility both to drought and to water logging. Although organic farmers use of less drastic means in pest control, yield reduction due to pest infestation was not more prevalent in organic fields. In most cases, the improved ecological balance and the preventive measures implemented in organically managed fields seem to hinder pest populations from building up. In addition, the tendency to maintain more diverse cropping patterns could render organic farms less vulnerable to adverse climatic and market conditions in the long term.

\section{Well-being}

Well-being is another important indicator for sustainable livelihoods. In order to operationalisethis general term, the definition is in line with the understanding of well-being of Amartya SEN. However, for this study the concept was generalized and is understood as freedom of choice and satisfaction in famers' daily lives.

While only one respondent reported to be happy and not needing any further support or facilities, all other farmers interviewed stated it to be difficult as a farmer. One explicitly mentioned that he wished to be only farmer, but due to little income from the farm, the family has to go for other jobs too. Another interviewee said to be satisfied with his work, but would require more land and irrigation facilities to suffice.

Overall it was found that it was government support such as subsidies, easily available loans or bigger acreage for marginal farmers the respondents wished for. To sum up, this indicator proved difficult to measure and analyse. Nevertheless, organic farming was found not only as a way of doing agriculture but also as a happy and positive attitude towards family and farm life.

\section{Discussions}

we discuss the results of the analysis of the five indicators of measuring sustainable livelihoods were earlier defined as employment, reduced poverty, wellbeing, less vulnerability and natural resource-based sustainability. With the help of the case study approach, four farms were selected in the district.

\section{Employment}

It was found that organic farming isnot a extra burden. However, out of four marginal farmers only one, farmer is a full-time profession. It was found that this farmer is the only lab our force in the household as compared to two to four members working on the farm in othercases. On the one hand it can be assumed that the labour force of one full-time farmer on a one-acre areca nut grove is sufficient to cultivate the land; on the other hand it needs to be taken into consideration that the requirements of a two- member household with no children are much less in comparison to the other families. Consequently all other farmers were forced to take up other jobs to cover household expenditures. 
As per the reviewed literature organic farming claims the opportunity for marginal farmers to be self-sufficient in their labour requirements. This holds partially true, as the farmers stated to hardly hire outside helpers. However, during harvesting time, most of them do need support. In the case of the paddy farmers and also of one areca nut farmer the exchange of labour is a popular, non-monetary supporting system. The organization promoting organic farming in this area supports these community activities. For organic marginal farmers this is an essential factor in saving expenses.

Another cost saving aspect was found in the production of goods for their own consumption. The reviewed literature as well as one informant stated the advantage of multi-cropping for a balanced nutrition of the farmer families. In the studied cases however these organic farming practices don't take place due to animal threats and lack of irrigation facilities. Nonetheless attempts for self-sufficiency were observed. One part of the sustainable livelihood outcomes is positive reputation among other community members. Although it was expressed in the reviewed literature that organic farmers are more educated and looked up to, some of the respondents encountered opposing chemical farmers.

To summarize, organic farming in the studied cases showed potential to fulfill the indicators for sustainable livelihoods. In particular strong communities for labour exchange and efforts to self-sufficiency in food production for own consumptions are favoring aspects of organic farming to achieve sustainable livelihoods. Nonetheless it is assumed that it is more difficult for marginal farmers with less than one acre to sustain a family of two or more members as compared to larger landholders. Moreover it is perceived that recognition by other farmers needs further education and extension efforts among neighboring chemical farmers. Also, mixed cropping practices are essential for both, income generation and food consumption.

\section{Poverty}

The reduction of poverty is another outcome of sustainable livelihoods, which is further sub-categorized into food security and safety, access to basic health care and education, water and sanitation as well as access to information.

In a nutshell, organic farming did not contribute significantly to poverty reduction in the studied cases. While there is potential to provide quality food for improved nutrition and health and decreased costs for food purchases, this holds only partially true in the selected farmer family which contributes to decrease in poverty in the long run.

\section{Natural resource-based sustainability}

The vulnerability aspect of sustainable livelihoods was limited to resilience to climatic shocks and calamities. This part of the study was found to be controversial in the interviews, as two farmers who claimed to be 100 per cent organic farmers stated to use chemicals in case of heavy rains to protect the areca nut plants against certain pests. The rice farmers used botanical surrogates but reported that in case of heavy rains neither organic nor chemical intervention will help and they will face a loss of yield. All of the respondents agreed on the fact that on a longterm basis, organic farming is however much more resilient to pests and climatic threats as the soil is healthier.
To encounter the natural disasters certain organic management techniques have been adopted such as Integrated Pest Management which includes biological control by natural predators, cultural methods, mechanical methods, bio-pesticides and use of herbal repellents. Further they confirmed that, the pest/disease control strategies suggested are mainly preventative rather than curatives

Itis found that these systems have helped preserve natural forests and biodiversity, being characterized by a high number of species of trees and birds. Organic production has led to the introduction of additional improvements, such as soil-conservation measures that are absent among conventional producers, thus improving the conservation of soils.

One of the farmer felt that, there is a mixture of cow urine and Varity of leaves from the forest to fight crop disease. As their experience earlier chemical used areca nut tress are very much susceptible to diseases.

It was found that the main objective of organic farming was toconservation of the soil for long lasting fertility of the land. On the one hand this was reasoned with the sustainability of the farm for future generations. On the other hand it is assumed that Hinduism and its principles plays an important role, as the land is perceived as the mother to all beings. Overall the paradigm of cutting costs rather than increasing income was found, which is closely related to a different way of life. Low-external input, food self-sufficiency and preventive measures to conserve soil fertility and enhance human health result in less expenditure. This distinct attitude to life needs to be created through augmented extension services. In the respective cases it was the NGO Krishi Prayoga Pariwara(KPP $\}_{\text {who primarily conducted training }}$ programmes on organic agriculture as a lifestyle in the area.

\section{Irrigation vs. Non irrigation facilities}

The implications of irrigation systems, it needs to be stated that there was a big divergence in the scale and efficiency of the irrigation facilities with the compared farmer in place. While the cash crop farmer had invested in an elaborate system arrangement, the interviewed paddy farmer owned a small farm pond with a pump and a few pipes, which he shared with his brother who owned the neighboring land. Hence, the given conditions do not prove viable to compare across the studied farms. However, on the basis of given responses during the interviews, broad comparisons can be drawn for further implications and recommendations.

Although Thirthahalli is seen with vast and timely rainfalls, all respondents stated the importance of offmonsoon harvesting primarily forproduction of goods for their own consumptions. Irrigation systems were found also essential for raise in their income with the families with children. While the areca nut farmer with facilities in place drastically increased his yield, the paddy farmer with a small farm pond can use irrigation only to grow few vegetables during summer season. He stated that suitable size facilities in place would allow him to harvest paddy twice instead of once a year, which would almost double his income.

The areca nut farmer family without access to irrigation in summer also wishes for those facilities to increase their yield. In case of marginal farmers the size of ponds and 
open wells however play an important role. Thus it was found that for marginal farmers with only half an acre of land couldn't place such facilities on his own land, as he would lose out on cultivable land. it is confirmed that as per their in situ cultivations experience that, organic inputs used areca nut and paddy along with inter crops requires very less amount of water as compare to conventional farming.

The case studies showed also that the farmers do not have sufficient financial resources to actually invest in such irrigation facilities.

\section{With and without government support}

While the farmers with government support were found to be rice cultivators from dalith background, the few farmers without benefits were Brahmin families growing areca nuts. Both of the selected farmers with government support were situated in the organic village, a project by KrishiPrayogaPariwara. As an NGO promoting organic farming, their primary activity is extension education among the farmers in this region. Consequently they have also facilitated the government schemes for marginal farmers. The government, through the organization provided granite cow shed flooring along with a special container for collection of cow urine and in one case toilet facility storage containers for paddy.

Some of the benefits were found more useful than others. One farmer did not use the cow urine collection system appropriately but gained from the paddy storage facility to keep rice dry for selling in times of money requirements and own consumption. However, the most wanted support by the government by those who already received assistance and those who don't was irrigation facilities. It must be concluded that the government benefits provide the farmers with additional support but do not offer essential relief in their livelihoods.

\section{Intervention of NGO}

Farmers felt that, KPP has encouraged and supported technical guidance for them and always motivating to take up innovative approaches through traditional knowledge in agro ecosystem management .further stressed the need of the hour to increase the capacity building trainings for the new farmers. Organic farmers requires a collaborative of other research organizations and expert NGOs they strongly argued that,. Progressive farmers should take lead role to actively involve the young farmers and make them to Visit successful model farms in nearby villages so that the same replica can be adopted with refined eco friendly techniques which must be suited to local agro climatic situations..

\section{Concluding observations}

Organic farming can contribute to sustainable livelihoods of marginal farmers, the case studies show high potential but not complete fulfillment of the indicators. While one-acre land or less does not yield enough to sustain the expenses of a family with children, the results indicate a possibility to live self-sufficiently for small farmers with one to two acres. Practices like multicropping would improve food-security and safety, reduce the expenses of the household and might decrease health care expenditures. Despite a desire to achieve a selfsustaining farm life across all cases, the studied households did not show sufficient resources. Primarily, all respondents who did not have efficient irrigation systems in place were reporting lack of access to those facilities as a hindering factor to attain sustainable livelihoods. With irrigation in place, their income as well as food production for their own consumption would increase. It is assumed that farm ponds and open wells collect abundant rainwater and would prove coherent with the sustainable livelihood indicator of natural resourcebased sustainability.

The studybroadly concludes that, the productivity and the environmental performance of organic agriculture in diversified agro climatic regions require further investigation. Research on and improvement of organic management practices under tropical and subtropical conditions is also needed. Organic agriculture research in developing countries should be through participatory technology centered- a inter face of various stake holders conducted with, identifying and taking into consideration their problems, needs and perceptions

In perspective of rural development this implies a different approach to poverty alleviation. While a main benefit of organic farming is currently seen in premium prices and improved marketing channels for those products to increase income, marginal organic farmers could achieve sustainable livelihoods through enhanced government support.

This study contributes to the wider body of knowledge in the field of organic farming and more specifically to private and public poverty alleviation programmes in rural India. It serves as a starting point for further investigation on the topic of sustainable livelihoods among marginal farmers and alternative poverty reduction approaches opposing merely growth induced development activities.

Although the study has shed some light on crucial points regarding the potentialof organicfarming. itcould only touch the surface, leaving a more in-depth investigation to other researchers.

\section{Acknowledgement}

The Author is thankful to organic farmers for co operation extended in the study area

\section{References}

[1] All India Report on number and area of operational holdings Agricultural census division phase-1 2014.

[2] UNDP (United Nations Development Program). (2001). Human Development Report. New Delhi: Oxford University Press.

[3] UNDP (United Nations Development Program). (2007a). Human Development Report 2007/2008: Fighting Climate Change.

[4] WB (World Bank). (2008a). Agriculture in India [online]. Accessed online May 2008.

[5] Veeresh G. K (2006). Organic farming: Enviornment and Development Series published by Foundation Books.

[6] Gehlot, Dushyent (2010) Organic Farming. Components and Management. Ghaziabad: Agrobios.

[7] Lampkin, N.H. (1990) 'Estimating the impact of widespread conversion to organic farming on land use and physical output in the United Kingdom', in Lampkin, N.H./Padel, S. (ed.) Economics of Organic Farming. UK: CAB International.

[8] Reddy, Parvatha, P (2008) Organic farming for sustainable horticulture: Principles and practices. Jodhpur: Scientific Publishers.

[9] World Bank (2007). World development report 2008: Agriculture for development. Washington DC.

[10] Scialabba, N. \& C. Hattam, Eds. (2002). Organic agriculture, environment and food security.Environment and Natural 
Resources Series. Rome, Food and Agriculture Organization of the United Nations (FAO).

[11] IFAD (2003). The adoption of organic agriculture among small farmers in Latin America and the Carribean - Thematic evaluation, International Fund for Agricultural Development (IFAD).Report No. 1337.

[12] IFAD (2005). Organic agriculture and poverty reduction in Asia: China and India focus. Thematic evaluation, International Fund for Agricultural Development (IFAD).Report No. 1664.

[13] Parrott, N., et al. (2006). Certified and non-certified organic farming in the developing world.Global Development of Organic Agriculture: Challenges and Prospects. Wallingford, Oxfordshire, UK, CAB International: 153-179.

[14] UNCTAD \& UNEP (2008). Organic agriculture and food security in Africa. New York and Geneva, United Nations Conference on Trade and Development (UNCTAD), United Nations Environment Programme (UNEP).

[15] Scoones, I.1998. Sustainable rural livelihoods: A framework for analysis. IDS Working Paper No. 72. Inst. Dev. Studies, Sussex, UK.
[16] Ellis, F. 2000. Rural livelihoods and diversity in developing countries. Oxford Univ. Press, UK.

[17] Hassanali, A., et al. (2008). Integrated pest management: the pushpull approach for controlling insect pests and weeds of cereals, and its potential for other agricultural systems including animal husbandry. Philosophical Transactions of the Royal Society B: Biological Sciences 363(1491): 611

[18] Sileshi, G., et al. (2008). Meta-analysis of maize yield response to woody and herbaceous legumes in sub-Saharan Africa.Plant and Soil 307(1): 1-19.

[19] Méndez, V. E., et al. (2010). Effects of fair trade and organic certifications on small-scale coffee farmer households in Central America Mexico.Renewable Agriculture and Food Systems 25(3): 236-251.

[20] Chen, X. P., et al. (2011). Integrated soil-crop system management for food security.Proceedings of the National Academy of Sciences of the United States of America 108(16): 6399-6404.

[21] Clough, Y., et al. (2011). Combining high biodiversity with high yields in tropical agroforests.Proceedings of the National Academy of Sciences 108(20): 8311-8316. 